\title{
Alphabetirdes Herzeidunis
}

\author{
der Gefeke mit den fundorten der eitzeluen Artikel und paragraphen.
}

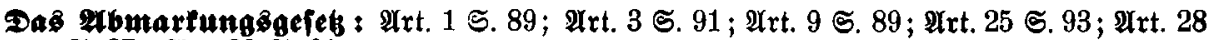
ธ. $87 ; \mathfrak{A r t} .29$ ؟. 91.

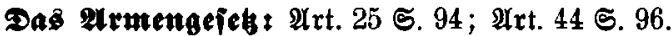

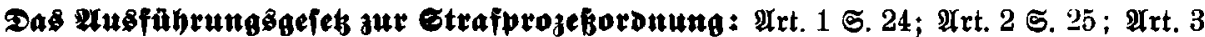

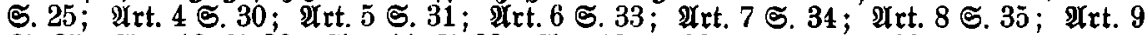

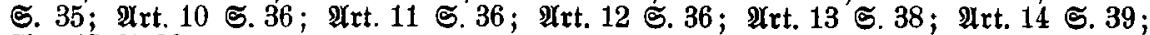
Art. 15 ธ. 39.

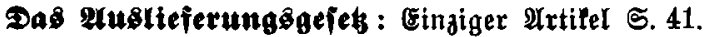

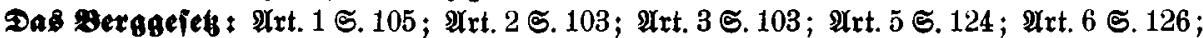

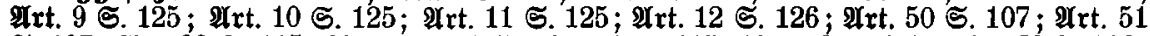

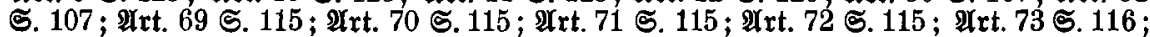

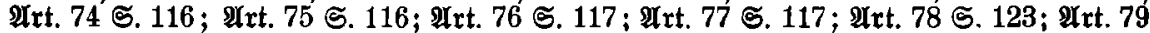

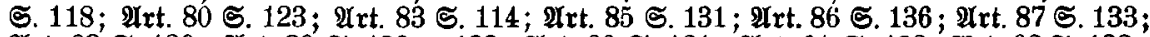

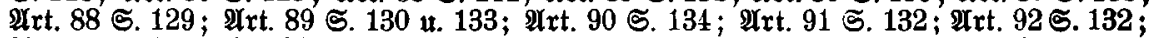

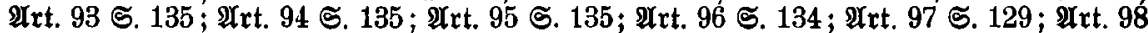

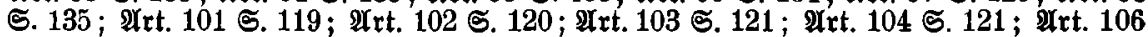

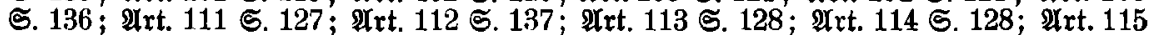

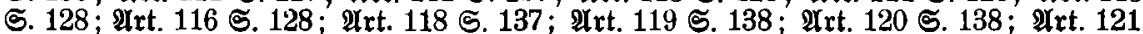

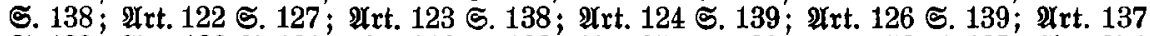

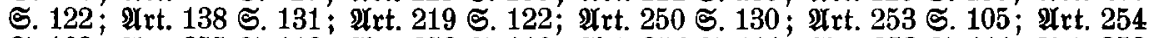

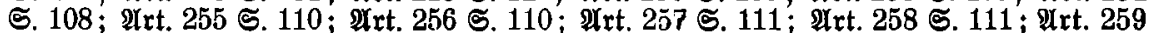

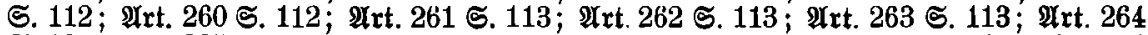

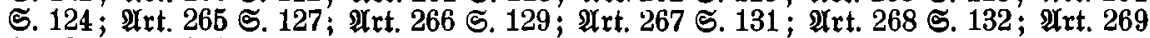

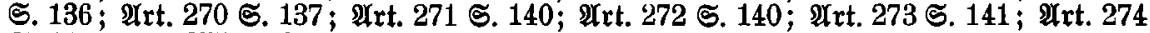
ธ. $141 ; \mathfrak{A}$ rt. 275 ธ. 241.

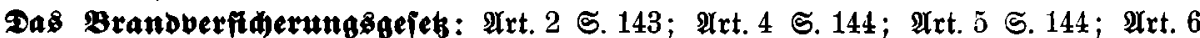

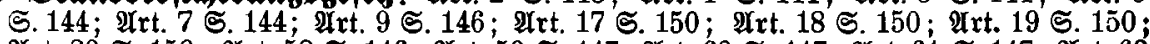

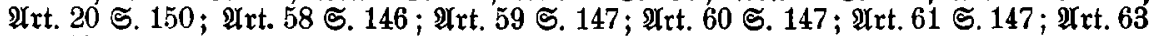
ธ. 149 ; $\mathfrak{U}$ rt. 96 ธ. 142.

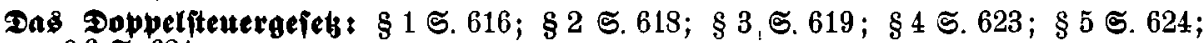
$\$ 6$ ङ. 624 .

Das Ctufâhrungsoefes su ben Gefeben aber ble diretten Steuern: Art. 1 S. 613 ;

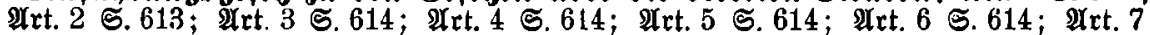
ऽ. $614 ; \mathfrak{A}$ rt. 8 ฐ. 615 .

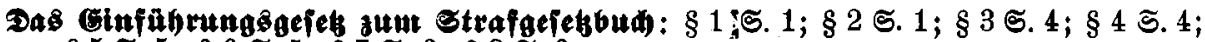
$\S 5$ ธ. $5 ; \S 6$ ธ. $5 ; \S 7$ ธ. $6 ; \S 8$ ธ. 6 .

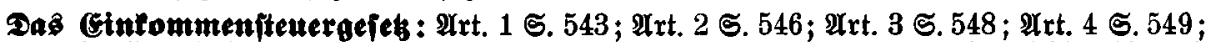

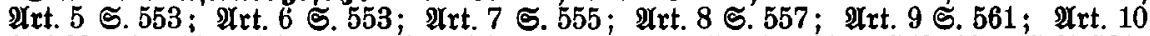

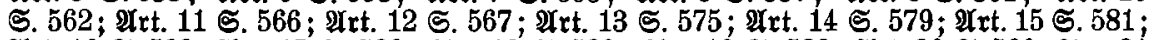

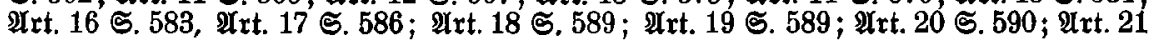

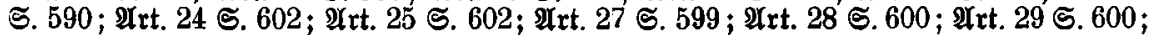

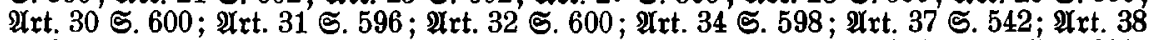

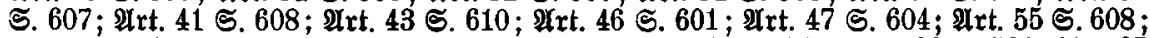

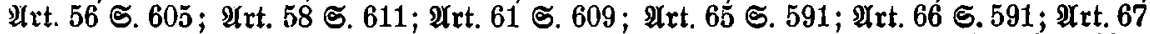

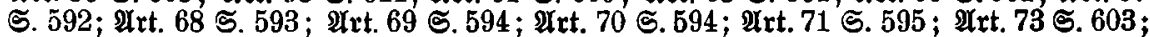

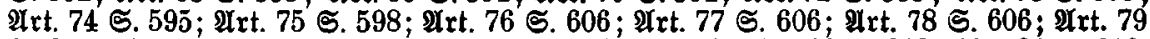

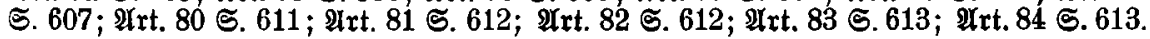




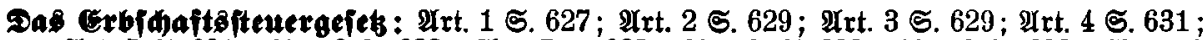

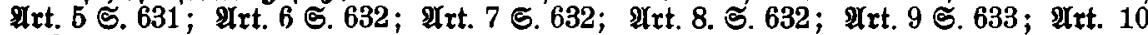

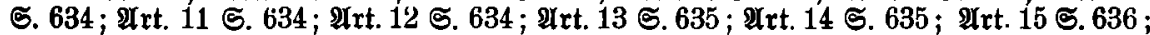

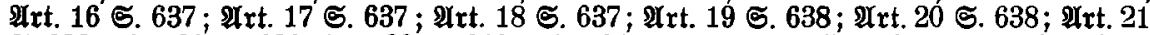

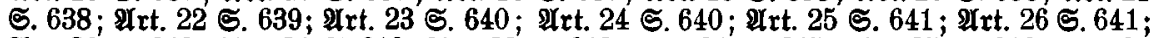

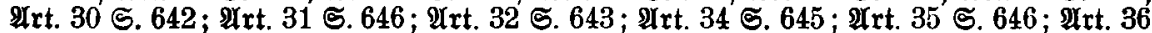

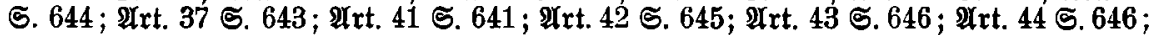
Îtrt. 45 $5.647 ; \mathfrak{A r t .} 46$ ऽ. 647 ;

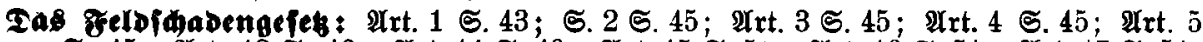

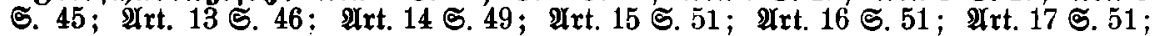

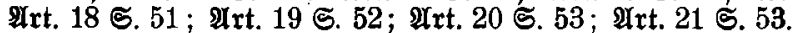

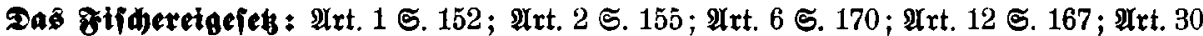

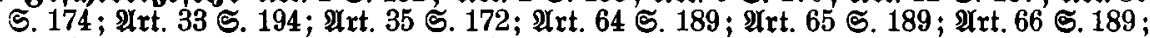

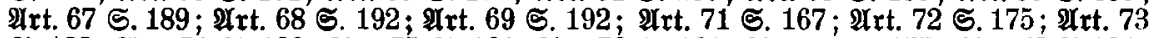

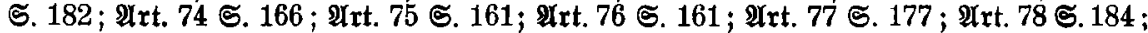

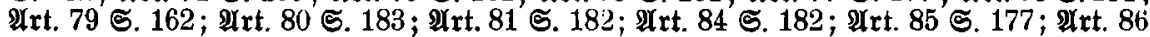

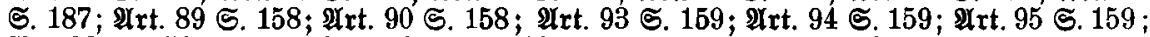

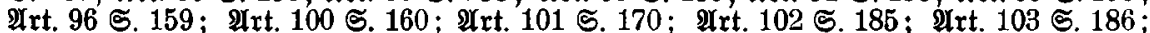

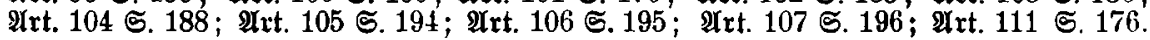

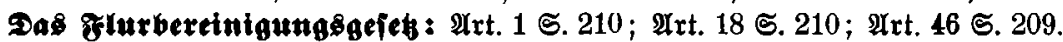

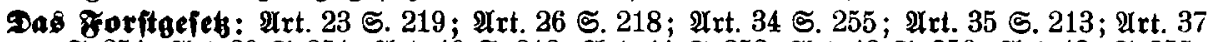

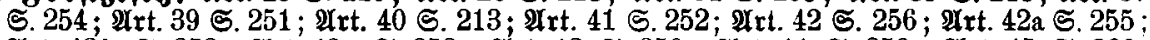

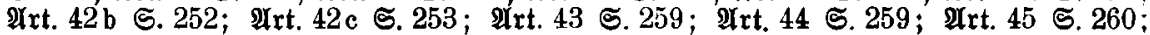

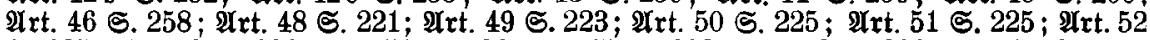

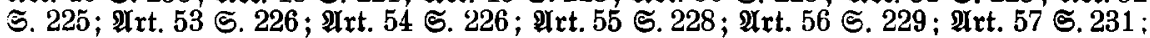

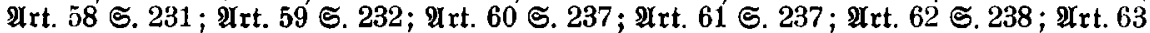

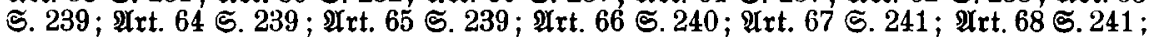

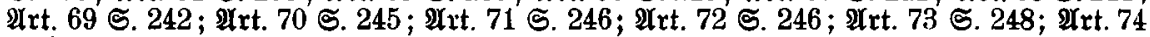

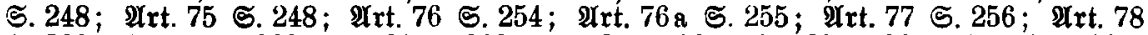

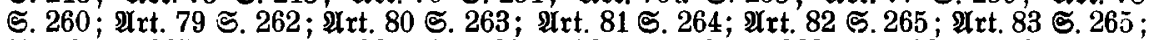

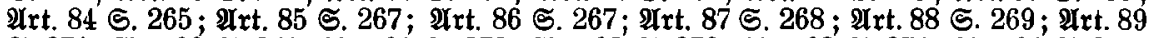

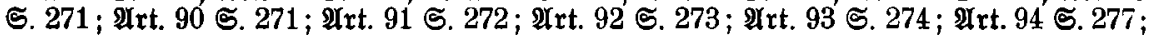

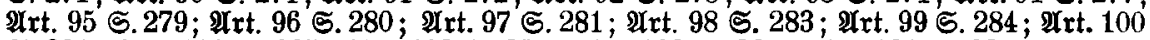

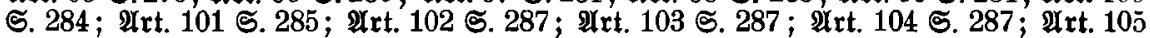

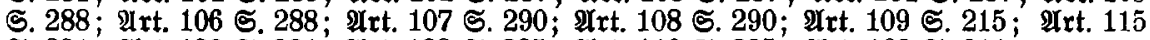

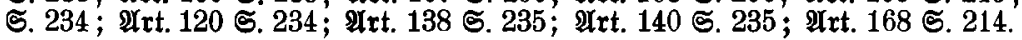

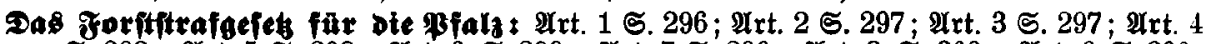

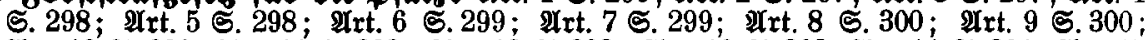

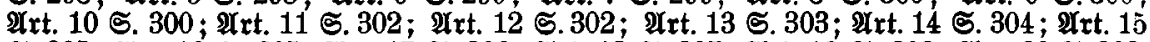

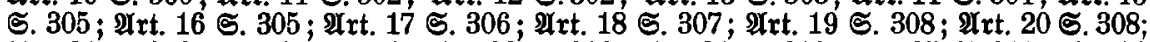

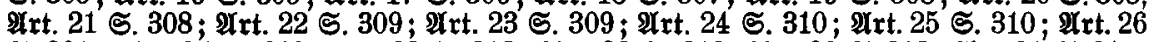

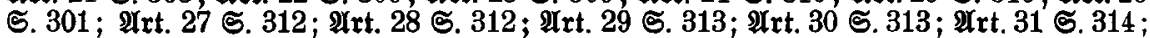

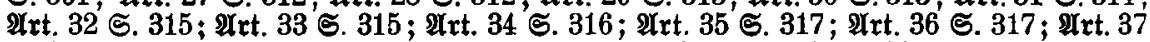

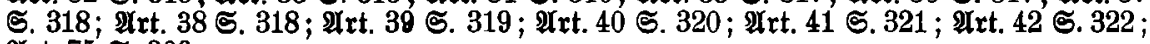
2rt. 75 ฐ. 306.

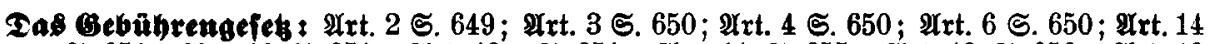

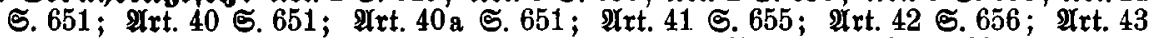

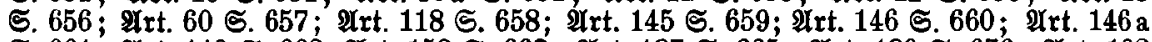

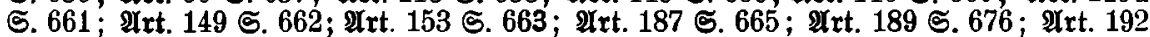

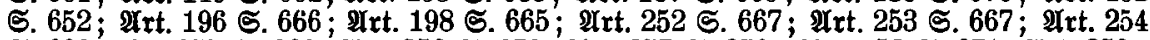

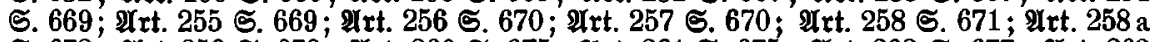

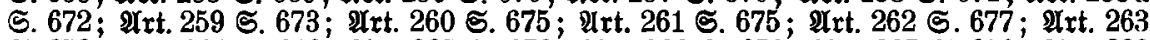

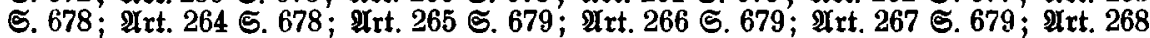

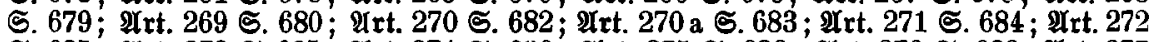

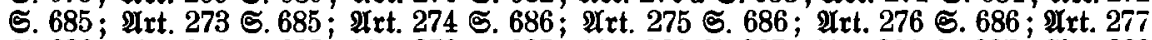

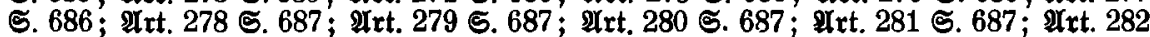

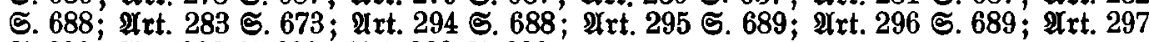
ธ. 690 ; Art. 298 ธ. 690 ; $\mathfrak{A r t . ~} 299$ ङ. 690.

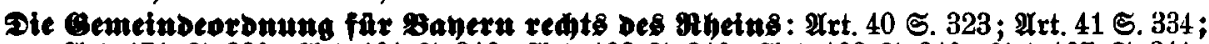

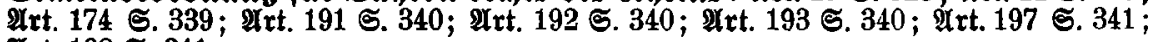
Art. 198 ธ. 341 . 


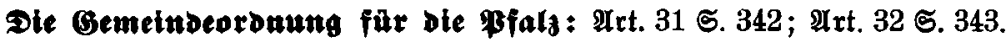

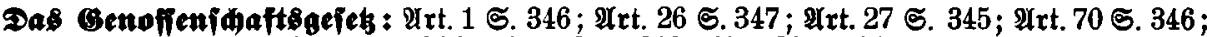

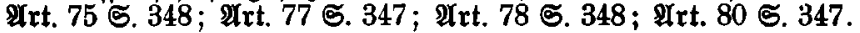

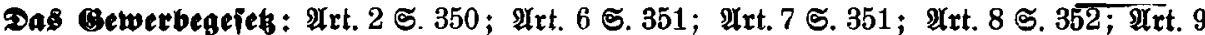

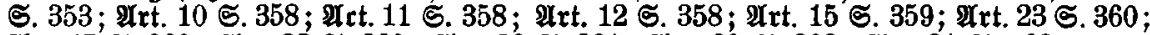

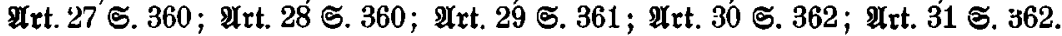

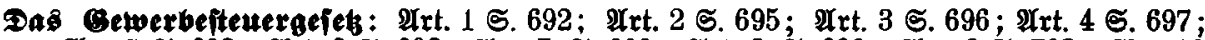

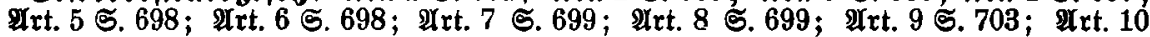

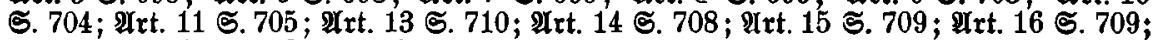

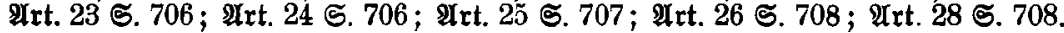

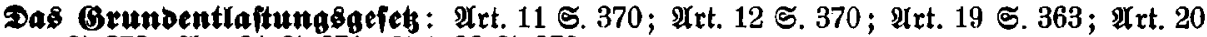

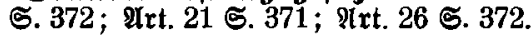

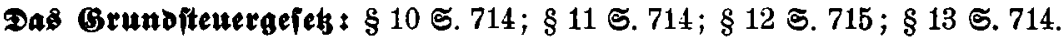

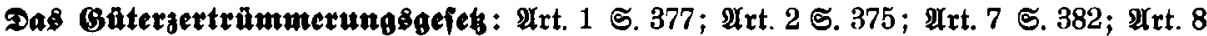

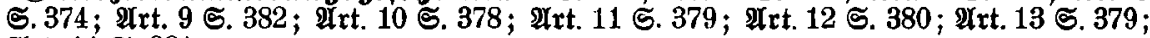
श्Art. 14 ฐ. 381.

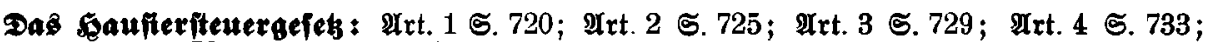

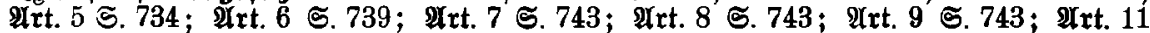

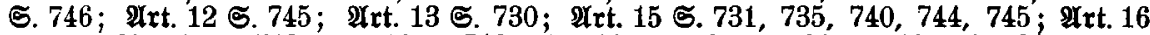

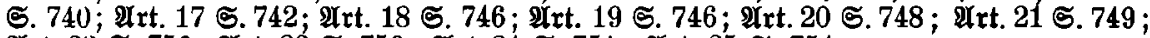

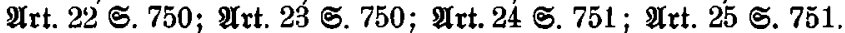

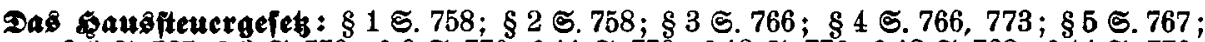

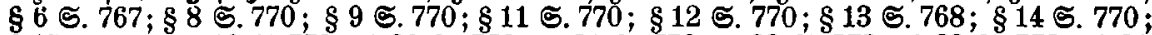

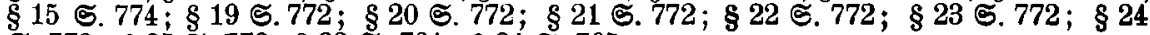
ธ. $772 ; \S 25$ ฐ. $773 ; \S 33$ ฐ. $764 ; \S 34$ ฐ. 765 .

Das setmatgejes: $\mathfrak{A r t .} 36$ ऽ. 385 ; $\mathfrak{A r t .} 38$ ธ. 387.

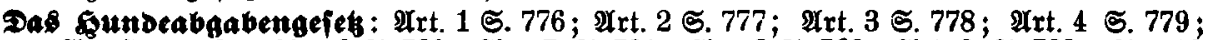

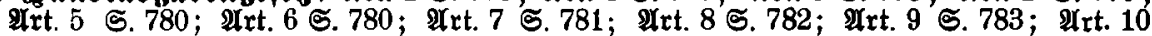

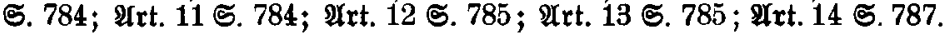

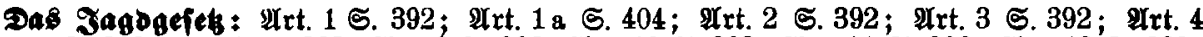

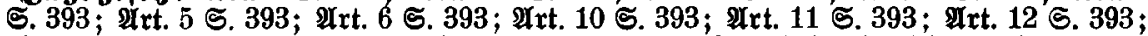

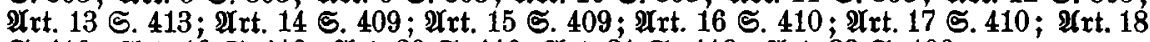

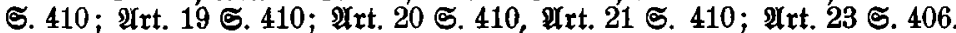

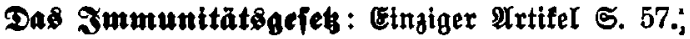

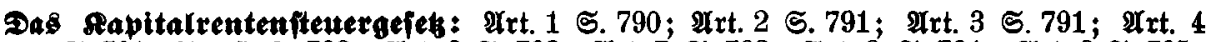

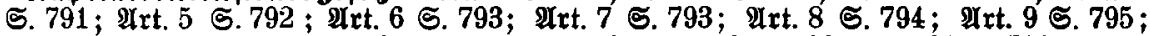

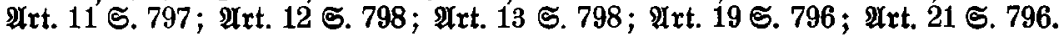

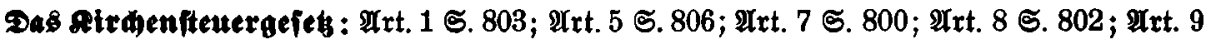

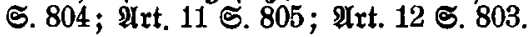

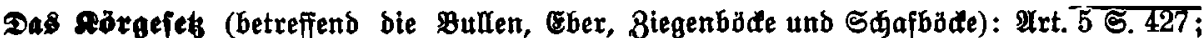

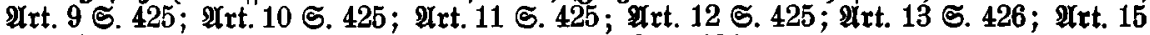

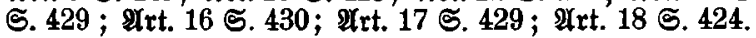

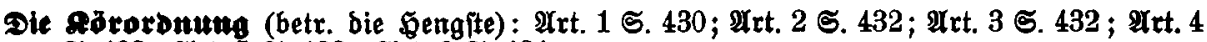

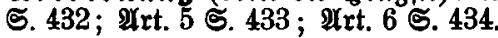

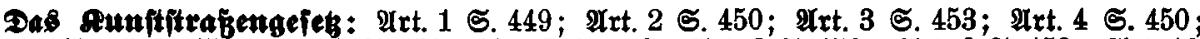

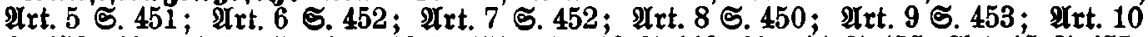

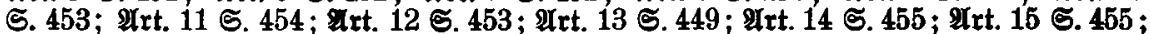

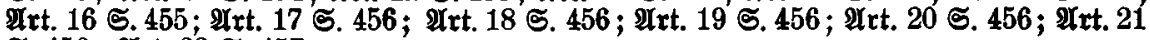
ธ. $456 ; \mathfrak{A}$ rt. 22 ฐ. 457 .

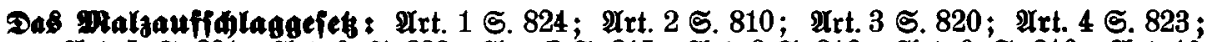

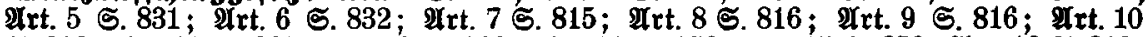

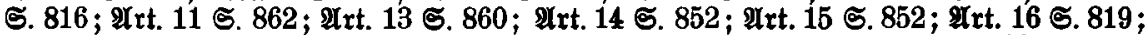

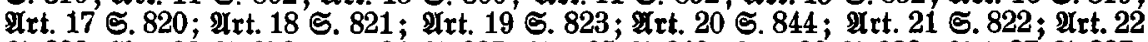

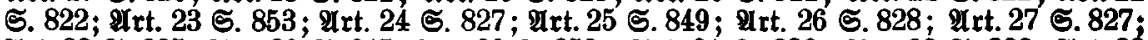

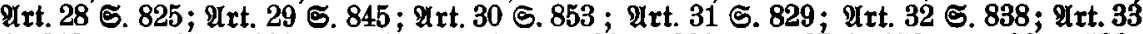

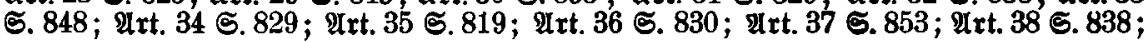




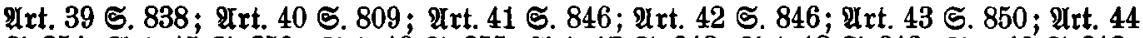

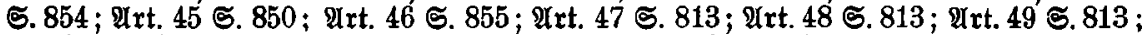

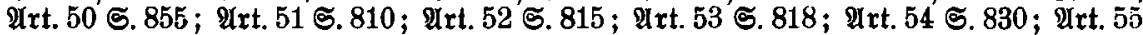

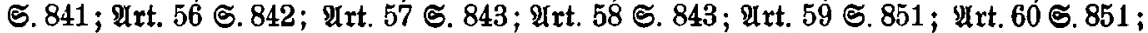

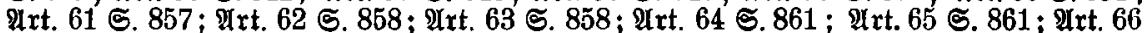

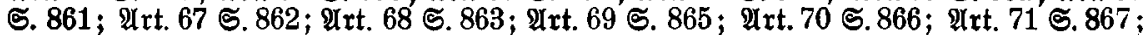

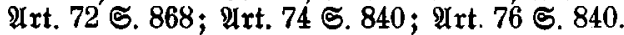

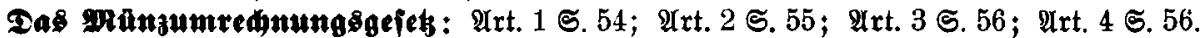

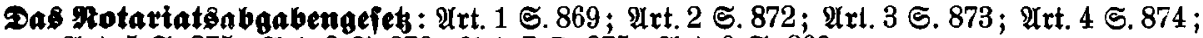

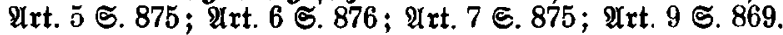

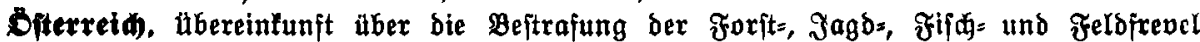
mit - ; 5.85.

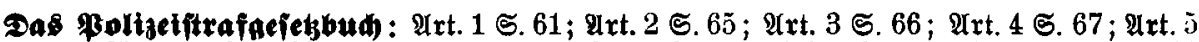

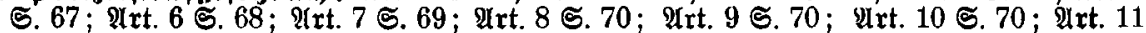

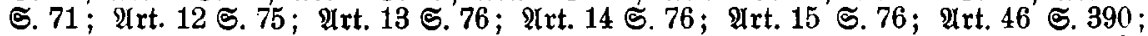

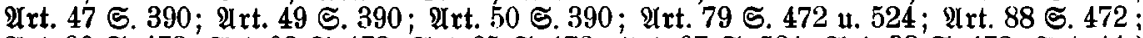

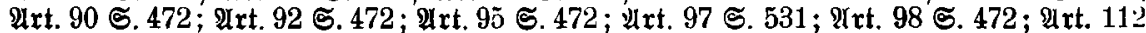

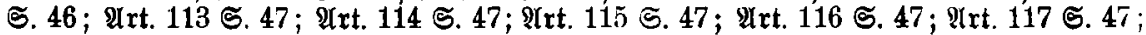

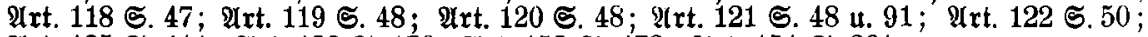

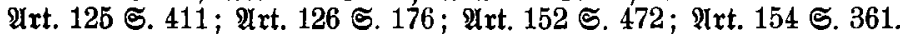

Das Straffolgengejes: Urt. 1 S. $82 ; \mathfrak{A r t .} 2$ S. $84 ; \mathfrak{A r t .} 3$ S. $84 ; \mathfrak{A}$ rt. 4 ฐ. 85 .

Das Pexetnogefes: Mrt. 4 5. 458 ; Irt. 20 S. 458 .

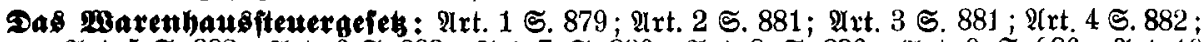

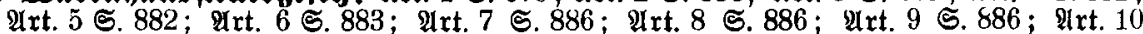

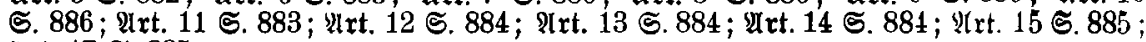
vitxt. 17 ऽ. 885 .

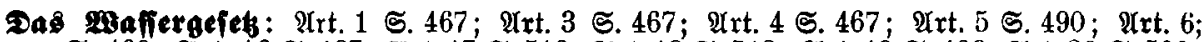

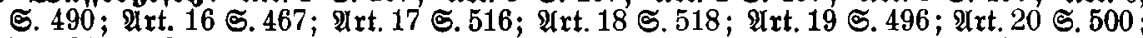

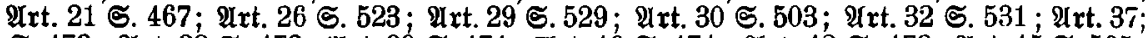

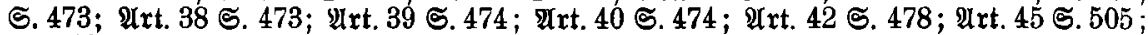

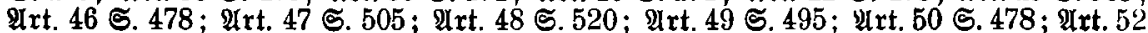

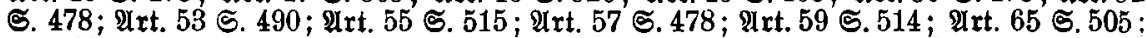

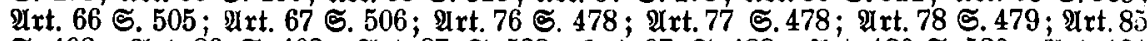

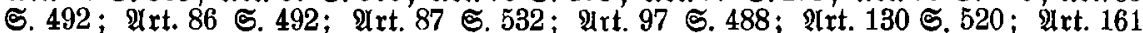

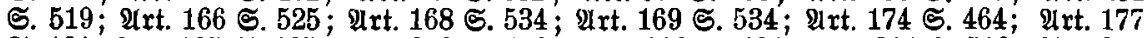

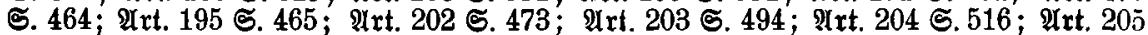

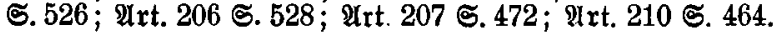

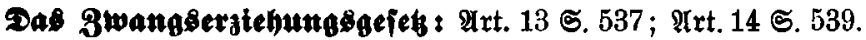

